\title{
ROMPER PARADIGMAS PARA CONSTRUÇÃO DE SOCIEDADES SUSTENTÁVEIS: AGROECOLOGIA NA FORMAÇÃO DE REDES, ECONOMIA LOCAL SOLIDÁRIA E POLÍTICAS PÚBLICAS
}

\author{
Bruno Oliveira Garcia ${ }^{1}$ \\ Luã Gabriel Trento² \\ Maraísa Resende Braga ${ }^{3}$
}

Resumo: O modelo capitalista neoliberal assim como seu paradigma epistemológico tem proporcionado diversas crises socioambientais. Não é diferente da atual crise sanitária, que revela a necessidade de se pautar outro modelo social. O Paradigma Agroecológico tem se consolidado dentro da epistemologia da Ecologia de Saberes, buscando superar os desafios alavancados desde a Revolução Verde. Assim, a partir da sistematização de reflexões elencadas pelo grupo Construção de Conhecimento Agroecológico da ABA, entendeu-se a necessidade de se engajar no fortalecimento de redes, na Economia local e Solidária e na promoção de Políticas Públicas estruturantes, em prol de Sociedades Sustentáveis.

Palavras-chave: Paradigma Agroecológico; Política Pública Estruturante; Ecologia de Saberes; Associação Brasileira de Agroecologia (ABA).

${ }^{1}$ Universidade de São Paulo. E-mail: garciabrunooliveira@gmail.com. Link para o Lattes: http://lattes.cnpq.br/6325970445210037

2 Universidade de São Paulo. E-mail: lua.trento@gmail.com. Link para o Lattes: http://lattes.cnpq.br/5143785240152335

${ }^{3}$ Universidade Federal de Santa Catarina. E-mail: bragamaraisa@gmail.com. Link para o Lattes: http://lattes.cnpq.br/8845804273644098 
Abstract: The neoliberal capitalist model, as well as its epistemological paradigm, offers several socio-environmental crises. It is no different from the current health crisis, which reveals the need for another social model. The Agroecological Paradigm has been consolidated within the epistemology of Ecology of Knowledge, seeking to overcome the challenges leveraged since the Green Revolution. Thus, from the systematization of reflections listed by the ABA Construção de Conhecimento Agroecológico [Agroecological Knowledge Building] group, understood the need to engage in strengthening networks, in the local and Solidarity Economy and in the promotion of structured public policies, in favor of Sustainable Societies.

Keywords: Agroecological Paradigm; Structuring Public Policy; Knowledge Ecology; Brazilian Association of Agroecology (ABA).

\section{Introdução}

\section{A desigualdade na pandemia}

A grave crise sanitária trazida pelo COVID-19 tem sacudido o mundo e escancarado a desigualdade social. No Brasil, basta olhar para os dados de boletins e relatórios (SÃO PAULO, 2020) sobre a pandemia para enxergar que ela tem se espalhado e causado maior impacto sobre as populações pobres. Fato este que já havia sido alertado por Mamelund (2017), pela negligência social nos planos e estratégias para lidar com pandemias, assim como doenças como diabetes e hipertensão. Davis (2020) aponta esta problemática como um dos três grandes desafios para lidar com a COVID-19, relacionando essa negligência ao legado da austeridade neoliberal que permitiu a diminuição de recursos investidos em redes de saúde pública agravando ainda mais os impactos desta pandemia. O município de São Paulo é um dos exemplos deste cenário. Os 6 Distritos Administrativos (DA) que estão com maior número de mortes causadas por COVID-19, de um total de 90 , são periféricos e estão entre os com menores Índice de Desenvolvimento Humano (IDH) (SÃO PAULO, 2020c).

Frente a este cenário caótico, as decisões governamentais expõem um lado nefasto do sistema capitalista na polarização entre os cuidados com a saúde da população e a manutenção do sistema econômico. Mesmo com as evidências científicas apontando que a melhor maneira de lidar com o vírus é evitando a contaminação através de medidas de quarentena, isolamento e restrição social, sobretudo em um cenário com poucas testagens ( $\mathrm{KOO}$ et al., 2020; LEWNARD; LO, 2020) há governantes anticientificistas que insistem em querer colocar a população em risco ao supervalorizar o sistema econômico, colocando-o como mais importante que a vida da população (GARRIDO; GARRIDO, 2020)

Tal dicotomia não deveria existir, contudo as atuais decisões políticas reafirmam privilégios a setores específicos. Este processo explicita questões invisibilizadas, que apontam para qual tipo de sociedade queremos e pretendemos construir: Uma sociedade em que a economia serve às pessoas

revista brasileira educação ambiental 
ou uma sociedade em que as pessoas servem à economia? É evidente que a atual lógica do capitalismo neoliberal exalta a perspectiva mercantilista, de que os seres humanos e não humanos, estão a serviço da economia (PEREIRA, 2011).

\section{Agronegócio e o Capitalismo Neoliberal}

Um dos grandes exemplos desse tipo de relação mercantilista é o modelo do Agronegócio. Com o passar do tempo, a humanidade desenvolveu técnicas mais ou menos conectadas com as potencialidades ecológicas locais, mas, a partir da implementação globalizada do Agronegócio pela Revolução Verde, se promoveu uma grande ruptura dos ecossistemas naturais, artificializando e generalizando os ambientes a fim de se obter o máximo rendimento de certas variedades de plantas e animais. A lógica de coprodução com a natureza foi completamente descartada para o emprego intensivo de agroquímicos, motomecanização pesada e de insumos industriais e fontes de energia não-renováveis (PETERSEN, 2015; PETERSEN; WEID, 2009). Esse modelo que se estabeleceu e expandiu após a Revolução Verde, atua a partir da lógica neoliberal capitalista. Goodman, Sorj e Wilkinson (1990) denominam as mudanças técnicas promovidas neste modelo de "apropriação industrial do processo natural de produção", que não apenas "reivindica parceria na determinação do ritmo de produção agrícola, mas também no ritmo dos processos sociais" (MARTINS, 2014. p.23).

A homogeneização genética e ecológica, bem como o confinamento animal, tornam os ambientes mais vulneráveis a insetos e doenças em geral. Ao invés de assumir a responsabilidade preventiva e atuar para tratar a raiz destes problemas, torna-se mais lucrativo movimentar todo o aparato químico e mecânico do agronegócio para remediar estes problemas, gerando ainda mais perturbações ambientais (ALTIERI; NICHOLLS, 2020). De forma geral, modelo tem promovido diversos problemas sociais e ambientais, entre eles a concentração de renda e de terras, o êxodo rural, aumento da vulnerabilidade e pobreza (FAO, 2016a, 2016b; MARQUES, 2018), além do desmatamento, da contaminação generalizada, da perda de biodiversidade, perda de solo, entre outros (IPCC, 2015).

As técnicas, inovações, práticas e políticas que permitiram aumentos na produtividade também minaram sua base. [...] em resumo, a agricultura moderna é insustentável - ela não pode continuar a produzir comida suficiente para a população global, a longo prazo, porque deteriora as condições que a tornam possível (GLIESSMAN, 2001, p.33).

Apesar das tecnologias aplicadas pela Revolução Verde terem aumentado a produtividade, essa produtividade, além de minar os sistemas ecológicos, não é voltada à qualidade de vida das pessoas. Ela tem como base 
valores do capitalismo, como o individualismo, a busca incessante pelo lucro, competição e meritocracia. A modernização impregnada no horizonte da sociedade e também imposta na Revolução Verde foi motivada pelo processo de acumulação capitalista e não no combate à fome e às desigualdades.

Nesse mesmo sentido, o desenvolvimento de "sistemas agrícolas de substituição eficiente" que envolvem a diminuição de impactos ambientais e alta eficiência produtiva, seguem a mesma lógica, pois se constroem no aproveitamento de um nicho de mercado (DURU et al., 2015, MAGRINI et al., 2019). Isto significa que não adianta apontar para uma agricultura de menor geração de carbono, ou para nova "revolução verde verde" (CAPORAL; COSTABEBER, 2004), pois não são suficientes para resolver os verdadeiros problemas, que são de base ética. Isto é, não adianta alimentos saudáveis se estes forem produzidos sob uma ótica de exploração humana e ambiental, reforçando as desigualdades.

\section{Na busca de um novo paradigma}

O paradigma da racionalidade econômica tende a reabsorver e redesenhar a economia dentro das estratégias de mercantilização, reduzindo a natureza a valor de suas "novas" funções, como provedora de riqueza genética, valor cênico, ou turístico (LEFF, 2002), ou seja, como "recursos". Essa associação, em que a humanidade é separada da natureza sendo apenas instrumento de dominação humana, dialoga com os pilares que sustentam a epistemologia hegemônica - e portanto, a ciência clássica-, que busca conhecer a natureza com intuito de a controlar (SANTOS, 1988).

A natureza aqui se torna um conjunto observável e passivo em relação ao observador (WEISS, 2014), da qual o método e o rigor científico se impõem como saber único e imediato. Com essas bases, firmes na razão analítica e lógica formal, essa ciência não consegue lidar com a existência da dialética entre observador e o objeto observado (BARBIER, 1985, p. 106), prevalecendo uma relação dualista do natural/artificial, subjetivo/objetivo, animal/natureza, etc. Essa lógica nega a racionalidade sobretudo daquilo que não se pauta pelos mesmos princípios epistemológicos, construindo ostensivamente uma barreira entre aquilo que seria o conhecimento científico, verdadeiro e correto e o não-científico, errado e irracional (SANTOS, 1988).

Essa ciência dominante, inserida dentro dos limites do capitalismo e da globalização hegemônica, ao se reconhecer como moderna, e portadora do único conhecimento válido, universal e fonte inesgotável de progresso tecnológico e de desenvolvimento, tem resultado em um "epistemicídio global" (SANTOS, 2010, p. 8), eliminando as várias formas de saberes locais. Para Santos (2010) essa racionalidade econômica, é uma forma de "pensamento abissal", demarcada pelo norte ocidental, do qual sustentam relações políticas e culturais, excludentes. "A injustiça social global estaria, portanto, estritamente 
associada à injustiça cognitiva global, de modo que a luta por justiça social global requer a construção de um pensamento 'pós-abissal'” (p.71).

O pensamento "pós-abissal" se constituiria fora da monocultura do saber, na busca de uma Ecologia de Saberes, onde a premissa fundamental é a diversidade epistemológica do mundo, promovendo a interdependência e interação entre os saberes científicos e outros saberes, não-científicos (SANTOS, 2007, 2010). Esse pensamento deverá seguir no rumo contrário das epistemologias eurocêntricas e se construir contrário ao patriarcado, ao capitalismo, ao imperialismo e à colonialidade do poder, na variedade dos projetos "históricos ético-epistémicos descoloniais" (GROSFOGUEL, 2009, p.413). Isso significa o exercício da pluralidade, diversidade e complexidade para novos encontros culturais (VISVANATHAN, 2009), que deverá emergir sob epistemologias do Sul (SANTOS; MENESES, 2009). Uma metáfora para se pensar a partir da perspectiva das principais vítimas do colonialismo e capitalismo global (BARRETO, 2014).

No mesmo caminho, Enrique Leff (2009) reforça a necessidade da ecologização dos saberes, para além da racionalidade econômica, do qual ele denomina "saber ambiental", onde se trabalha com a complexidade, na vinculação entre os potenciais ecológicos, a criatividade e diversidade dos povos.

A complexidade ambiental emerge da relação entre o real e o simbólico; é um processo de relações ônticas, ontológicas e epistemológicas; de hibridações da natureza, da tecnologia e da cultura; é, sobretudo, a emergência de um pensamento complexo que apreende o real e que se torna complexo pela intervenção do conhecimento (LEFF, 2009, p.22).

Esse saber ambiental teria o potencial de impulsionar uma utopia de "reconstrução da realidade a partir de uma multiplicidade de sentidos individuais e coletivos", de "intersubjetividades e de saberes individuais" (LEFF, 2009, p. 18). Essas dimensões subjetivas trazem a revalorização das necessidades e desejos humanos, como a dignidade, felicidade, espiritualidade e qualidade de vida (PEREIRA, 2011), geralmente colocados como subalternos à dimensão econômica. $\mathrm{O}$ que reforça parte da crise humanitária, que seria a "crise de utopia", da perda da capacidade de sonhar (MAX; ELIZALDE; HOPENHAYN, 1986).

o que é econômico e momentaneamente lucrativo não é, necessariamente 0 que melhor expressa os valores sociais relativos à constituição do humano, à humanização do homem, e à superação de suas carências (...) a modernização econômica não as provê nem as supre (MARTINS, 2014, p. 24). 
Essas perspectivas trazem a noção do fortalecimento da epistemologia a partir da diversidade de saberes e das suas inter-relações. É uma mudança paradigmática, que propõe a necessidade de olhar a partir da complexidade ambiental e das intersubjetividades, na promoção de Sociedades Sustentáveis. Segundo Diegues (2003, p.1-2)

A construção de comunidades e sociedades sustentáveis deve partir da reafirmação de seus elementos culturais e históricos, do desenvolvimento de novas solidariedades, do respeito à natureza não pela mercantilização da biodiversidade, mas pelo fato que a criação ou manutenção de uma relação mais harmoniosa entre sociedade e natureza serem um dos fundamentos das sociedades sustentáveis.

\section{Paradigma Agroecológico}

O surgimento do conceito da Agroecologia aparece inicialmente numa tentativa de aproximar a agronomia das disciplinas de ecologia (WEZEL et al., 2009). Essa aproximação, já com Bensen na década de 1930, veio num contexto de uso indiscriminado de insumos artificializados e que com o passar do tempo foi se desenvolvendo para além das particularidades técnicas instrumentais e se voltando cada vez mais para uma complexidade relacional entre o social, ecológico e técnico. (GLIESSMAN, 2013).

Um dos grandes contribuintes do entendimento da Agroecologia passa pelos movimentos ambientalistas na década de 60 , que imbuiram uma perspectiva crítica e de mobilização social (HECHT, 1993). A partir de então, ela passa a integrar um dos eixos conceituais, conjuntamente com a perspectiva da Ciência e das práticas. Segundo a Associação Brasileira de Agroecologia (ABA), a Agroecologia é definida como:

ciência, movimento político e prática social, portadora de um enfoque científico, teórico, prático e metodológico que articula diferentes áreas do conhecimento de forma transdisciplinar e sistêmica, orientada a desenvolver sistemas agroalimentares sustentáveis em todas as suas dimensões (2015, pg.1).

Gliessman (2013) reforça que a Agroecologia deve integrar ciência, tecnologia, prática e movimentos para mudança social, já que uma separação dessas seria senão uma forma de artificialização dessas três dimensões, que tende a descolar a perspectiva política e a simplificar em técnicas. Não é à toa que, já em 1989, Norgaard (1989) trazia que, pensar Agroecologia, é pensar em epistemologia e reforçava que essas bases epistemológicas deveriam estar em contraponto com a visão ocidental mecânica do mundo, para galgar dentro 
do campo do conhecimento onde, tanto a cultura humana quanto os sistemas biológicos, são inseparáveis.

Assim, a Agroecologia nasce no contexto das Epistemologias do Sul, trazendo saberes invisibilizados que se forjam na interface entre diferentes cosmovisões, teorias e práticas (LARANJEIRA et al., 2019; LEFF, 2009). Em termos epistemológicos ela indica esse novo paradigma que privilegia conhecimentos contextualizados, e onde o diálogo e as relações horizontais atuam no sentido da Ecologia de Saberes (LARANJEIRA, 2019).

Agroecologia, associada à esses três processos imbricados, movimento social, ciência e técnica, e tendo suas bases epistemológicas no Saber Ambiental e na Ecologia de Saberes parece um caminho concreto no enfrentamento dos principais problemas socioambientais alavancados pela lógica do capitalismo neoliberal e que hoje se escancara, em alguns aspectos, pela crise sanitária desencadeada pelo surgimento do COVID-19.

\section{Enunciando Caminhos}

No Brasil, o movimento agroecológico avançou expressivamente com o surgimento da Associação Brasileira de Agroecologia (ABA), que atua em diferentes esferas no campo da Agroecologia, em consonância com a Articulação Nacional de Agroecologia (ANA), envolvendo diversos atores sociais e incidindo em ações junto a instituições governamentais e não governamentais, nas várias escalas territoriais (DA COSTA et. al., 2015).

A ABA se organiza a partir de uma diretoria com representações nacional e estaduais, além de Grupos de Trabalhos (GTs) espalhados pelo território nacional. Os GTs têm a função de criar redes de diálogo permanente sobre determinados assuntos, como: agrotóxicos; transgênicos; campesinato, soberania alimentar; ancestralidade; educação; gênero, saúde e outros. $\mathrm{Na}$ direção de aprofundar sobre os processos de construção dos saberes Agroecológicos, a ABA, em 2011, criou o GT "Construção do Conhecimento Agroecológico" que ao longo do tempo tem procurado

incentivar processos, metodologias e práticas que contribuam para a indissociabilidade entre ensino, pesquisa e extensão na perspectiva da ecologia de saberes e para o desenvolvimento de uma ciência contextualizada, que contribua para a promoção de sistemas agroalimentares sustentáveis (LARANJEIRA, 2019, p.66). 
acontecendo os processos de construção de conhecimento. Com isso, o grupo elencou algumas questões problematizadoras, a fim que os integrantes que compõem o GT, pudessem exercitar uma sistematização crítica reflexiva dentro dos territórios que atuam. As perguntas abordavam questões relacionadas à identificação das iniciativas; ao diálogo e articulação entre elas; ao contexto de seu surgimento; aos atores sociais envolvidos e seu acesso e voz e aos principais desafios e potencialidades para o momento.

A partir disso, compilou-se os conteúdos discutidos, buscando sistematizá-los em tópicos, e evidenciando as principais oportunidades estratégicas e desafios enfrentados neste momento. As respostas foram elencadas na Tabela 1.

Tabela 1: Tópicos elencados sobre os principais desafios e oportunidades conjunturais ao início da pandemia produzidos pelo GT da ABA Construção do conhecimento agroecológico.

\begin{tabular}{|c|c|}
\hline & Principais desafios \\
\hline & $\begin{array}{l}\text { Práticas muito emergenciais que dificultam a } \\
\text { reflexão e sistematização das iniciativas }\end{array}$ \\
\hline & $\begin{array}{l}\text { Dificuldades no uso e apropriação de } \\
\text { tecnologias. }\end{array}$ \\
\hline & Elencar prioridade nas ações \\
\hline & $\begin{array}{l}\text { Falta de financiamento para execução dos } \\
\text { projetos (muitos voluntários/as, pouco } \\
\text { recursos financeiros). }\end{array}$ \\
\hline & Dar a voz direta aos sujeitos do campo; \\
\hline & $\begin{array}{l}\text { O distanciamento das relações inter- } \\
\text { relacionais (comunicação apenas vias online) }\end{array}$ \\
\hline & $\begin{array}{l}\text { Cair em armadilhas futuras, como a } \\
\text { "uberização" das relações }\end{array}$ \\
\hline & Falta de financiamento público \\
\hline & Paralisação de políticas públicas \\
\hline & $\begin{array}{l}\text { Contaminação de agricultores/as por falta de } \\
\text { Equipamentos de Proteção Individual (EPI). }\end{array}$ \\
\hline & $\begin{array}{l}\text { Estrutura logística na separação e distribuição } \\
\text { dos produtos agrícolas }\end{array}$ \\
\hline & $\begin{array}{l}\text { A cultura alimentar associada à } \\
\text { Ultraprocessados }\end{array}$ \\
\hline
\end{tabular}

\begin{tabular}{|l|}
\hline \multicolumn{1}{|c|}{ Principais oportunidades e ações } \\
\hline $\begin{array}{l}\text { Mapeamento de iniciativas e diálogo entre } \\
\text { elas }\end{array}$ \\
\hline Atuação em Rede \\
\hline Pressão para acesso à políticas públicas \\
\hline $\begin{array}{l}\text { Criação de novas Políticas Públicas e } \\
\text { aprimoramento de políticas como: PNA; } \\
\text { PAA; de Reforma Agrária; etc. }\end{array}$ \\
\hline $\begin{array}{l}\text { Criação e uso de Tecnologias Apropriadas } \\
\text { para pequenos agricultores }\end{array}$ \\
\hline $\begin{array}{l}\text { Desenvolver processos educadores voltados à } \\
\text { voz e autonomia dos sujeitos do campo }\end{array}$ \\
\hline $\begin{array}{l}\text { Adequação da legislação sanitária para } \\
\text { contexto da Agricultura Familiar }\end{array}$ \\
\hline $\begin{array}{l}\text { Aumentar as redes de consumo direto } \\
\text { Desenvolver processos educadores voltados à } \\
\text { Cultura alimentar }\end{array}$ \\
\hline
\end{tabular}

Fonte: Grupo de Trabalho, Construção do Conhecimento Agroecológico, da Associação Brasileira de Agroecologia (ABA). 
Os tópicos enunciam alguns desafios que podem até parecer pontuais, mas que só se sustentam por problemas estruturais, potencializados pela lógica neoliberal capitalista. A partir dos diálogos desenvolvidos pôde-se evidenciar problemas relacionados com o modelo de construção de Políticas Públicas e, como estas são apropriadas pelos atores sociais. Também, apresentou-se, a demanda de fortalecer o engajamento em redes, buscando diminuir elos de dependência e aumentando a autonomia e segurança social. Nesse mesmo caminho, emergiu a necessidade da construção de processos e tecnologias contextualizadas, assim como, no fortalecimento de relações interpessoais.

Esse movimento praxiológico, de ação-reflexão-ação, sobre as iniciativas em a Agroecologia, está permeada pela busca de potencializar ações concretas e observar, constantemente, a necessidade de rever para as bases que sustentam esse modelo, na tentativa da superação objetiva e subjetiva da exploração humano-natureza. Essa reflexão nos conduziu a sintetizar três eixos indissociáveis (Figura 1) e necessários, ao nosso ver, para que os movimentos ambientalistas e agroecológicos caminhem no rompimento com a lógica neoliberal, rumo à soberania alimentar e à transição de Sociedades Sustentáveis.

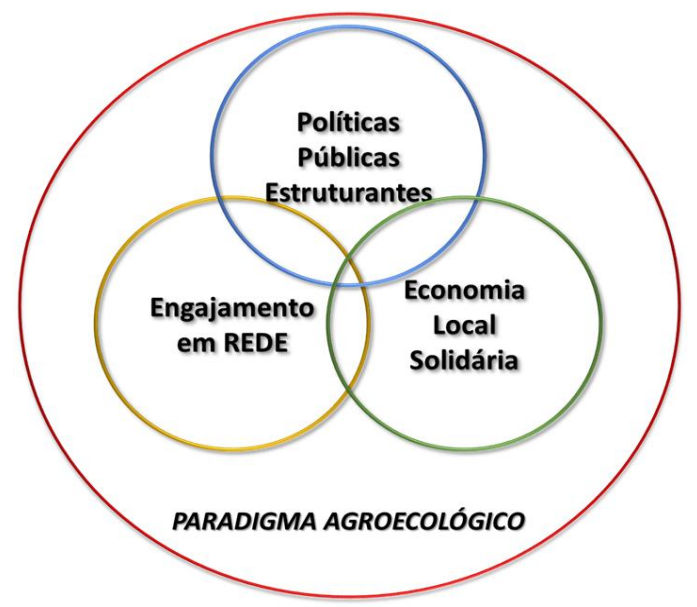

Figura 1: Diagrama de Venn mostrando a relação entre os pilares indicados como indissociáveis à atuação do movimento agroecológico nesta conjuntura.

\section{Economia Local e Solidária}

Uma sociedade que levasse o individualismo e a competição como norma de sociabilidade às últimas consequências pereceria em pouco tempo. Alguma solidariedade, alguma interação desinteressada e altruísta é indispensável à reprodução de qualquer sociedade (SINGER, 2001. p. 100) 
vigente. Esta é uma das contradições imposta na economia capitalista, e é neste contexto que se fundamenta a atuação da Economia Solidária. Elas abrem espaços e criam oportunidade para o desenvolvimento de organizações cuja a lógica é oposta ao modo de produção dominante (SINGER, 2002).

De maneira geral, estas novas organizações, também entendidas como empreendimento solidários, devem seguir os princípios da solidariedade, sustentabilidade, da inclusão, da emancipação. Princípios éticos-políticos antagônicos ao dos negócios capitalistas, que beneficiam apenas seus proprietários (GADOTTI, 2009). Seu principal objetivo consiste na reorganização social de modo a assegurar condições materiais mínimas enfatizando a participação coletiva, cooperação, autogestão, democracia, auto sustentação, a promoção da equidade de gênero e a responsabilidade com a preservação do equilíbrio dos ecossistemas (MANCE, 2005).

Neste contexto, vale ressaltar que a economia solidária não é e nem deve ser vista, como uma compensação à economia capitalista (SINGER, 1996). Ao contrário, ela nasceu como uma alternativa a esse modelo e corrobora com um movimento mais amplo que pauta mudanças profundas que possibilitem a reestruturação produtiva a partir de valores contrários ao das economias capitalistas (GADOTTI, 2009).

A crise do modelo capitalista fragmentou as classes trabalhadoras, tornando ainda mais desiguais as relações de poder. Essa característica enfatiza a importância destes empreendimentos no processo de acolhimento daquelas pessoas excluídas das organizações hierárquicas e centralizadas, e também sugere o trabalho em redes como a única condição de sobrevivência a este ambiente típico das economias capitalistas. (GADOTTI, 2009)

Neste sentido, a Economia Solidária deve emergir como um "embrião de um novo projeto de sociedade" (GADOTTI, 2009), uma "alternativa superior ao capitalismo", que aponte para uma vida melhor, não no sentido de aumentar o poder de consumo e diminuir o esforço produtivo, mas no sentido de melhores relações interpessoais, "na segurança de cada um saber que sua comunidade jamais o deixará desamparado" SINGER (2002, p.115).

A Economia Solidária aqui é reforçada com uma centralidade de atuação local. As primeiras iniciativas que se preocuparam com a econômica local apareceram a partir da preocupação com o processo de industrialização do meio rural e do estabelecimento dos grandes aglomerados empresariais, monopolizando o sistema agroalimentar. Na literatura, as tentativas de categorização acabam se sobrepondo e trazendo diferentes denominações, como sistema alternativo, circuito curtos, circuito de proximidades, entre outros. (CANELLAS; ALVES, 2017).

Dentre as definições mais comuns encontradas na literatura, podemos citar aquela que ressalta a perspectiva espacial e se restringe apenas ao número de atravessadores que existem entre o/a produtor/a e o/a consumidor/a (CHAFOTTE; CHIFOLLEAU, 2007, apud DAROLT, 2013). De maneira prática 
esta proposta simplifica a definição deixando pouca margem para a subjetividade, porém, neste contexto de superação de paradigmas, não nos parece pertinente se restringir a quantidade de atravessadores, uma vez que está também tem sido uma estratégia de apropriação dos grandes aglomerados empresariais para diminuir os preços e aumentar ainda mais suas margens de lucro (GUZMAN, 2012).

Logo, assumimos a importância de que a economia local para além das restrições espaciais, mas que pressuponham sistemas de produção, beneficiamento e circulação, socialmente enraizado, orientado pela construção coletiva e baseado na solidariedade, horizontalidade e confiança (PEREZ CASSARINO; DAMASCENO 2013). É essencial que estes circuitos estejam fundamentados em valores éticos de governança, para permitir a melhoria das condições de vida (GUZZATI 2014; DAROLT, 2013).

Se torna evidente a indissociabilidade entre os temas de redes e Economia local e Solidária. Nos últimos anos as experiências de redes agroecológicas e Economia Local Solidária vêm se destacando, tanto pela internalização da lógica da reciprocidade, como da construção da cidadania ambiental e dos processos de inclusão social daqueles indivíduos excluídos do mercado formal de trabalho (FARIA 2012, SILVEIRA, 2013a). Como ressaltado por Petersen; Arbenz (2018), a verdadeira implementação de sistemas agroecológicos necessita de organização de redes alimentares locais que promovam o desenvolvimento territorial. Darolt (2013, p. 165) complementa, afirmando que as iniciativas de circuitos curtos que deram certo, em geral, aconteceram "em locais onde se verifica a formação de uma rede com estreita interação entre poder público, entidades não governamentais, organização de agricultores e participação de consumidores".

\section{O Engajamento em redes}

Criar, construir e aprender, a cada dia, a compartirmos e compartilharmos não apenas as alegrias da vida, mas também o trabalho solitário que torna e há de tornar mais fecunda, mais harmoniosa e mais feliz esta mesma vida humana que nos é dado viver em algum lugar da Terra, durante algum tempo na sua História (BRANDÃO, 2017. P. 180)

Ainda neste mesmo texto, Brandão fala sobre a importância do trabalho em rede para o movimento ambientalista:

As pessoas aprendem os segredos da convivência e desenvolvem, dia após dia, uma crescente consciência de partilha, cooperação e solidariedade. Não é raro que uma pessoa diga o quanto passou de "competitiva" a "cooperativa", de "interesseira" a "gratuita e generosa", de "individualista" e "passiva" a "participante e ativa" e de "solitária" a "solidária", 
não tanto pelo que leu e estudou, mas pelo que viveu e conviveu em uma equipe de trabalhos de um movimento social (BRANDÃO, 2017. p. 185).

As palavras de Brandão citadas acima nos ajudam a enxergar a profundidade e importância de relações engajadas que se estruturam em relações solidárias. Silveira $(2013 b)$ propõe uma definição para o conceito de rede que converge com o que foi apresentado acima. A autora inicia afirmando que este conceito é parte de uma teoria sistêmica mais complexa que vem se desenvolvendo desde o século XX e complementa, definindo que:

De modo geral, o conceito de rede faz referência a horizontalidade, ao encadeamento, a interdependência, a conectividade, a flexibilidade, significando ainda articular-se e retroalimentar-se. As redes de organizações são espaços de mobilização, articulação política, troca de informação, compartilhamento de propostas, enfim visam fortalecer os atores e potencializar suas ações em torno de uma meta, uma pauta/objetivo comum (SILVEIRA, 2013b. p. 63).

De uma maneira mais pragmática, podemos assumir que a proposta de uma organização horizontal se relaciona de maneira antagônica aos princípios capitalistas. Mance (1999) contribui para fortalecer este argumento quando traz como condição da gestão das redes, a descentralização, a gestão participativa, a coordenação eleita democraticamente e por fim, a regionalização, assumindo seu papel de influência nos territórios locais. Neste contexto que o engajamento em rede e as iniciativas de Economia Solidária e local se relacionam de maneira indissociável e assumem o protagonismo em um movimento maior que pauta mudanças estruturais mais profundas na maneira como nos relacionamos.

Esta contextualização trouxe elementos que relacionam a atuação em redes com as propostas de Economia local e Solidária, é importante acrescentar reflexões da centralidade ambiental, como por exemplo, o fato de que cooperativas podem contribuem para a estabelecer melhores condições de equilíbrio nos agroecossistemas KROLOW (2005). Além da importância, trazido por FARIA 2012, como o principal fator de influência na ação dos produtores rurais da rede Justa Trama. Em consonância com este discurso Abramovay (2000), recomenda que as redes devem assumir o protagonismo da pauta ambiental junto do resgate às tradições, não como uma restrição ou freio as transformações sociais, mas como inspiração para fundar modos de vida "alternativos". 


\section{Políticas Públicas Estruturantes}

Não existe uma única ou melhor referência sobre políticas públicas, a definição mais conhecida é a proposta por Laswell, que implica em responder três questões: quem ganha o quê, por que e que diferença faz. (SOUZA, 2006). Além desta referência, Dye (2009) propõe de maneira bastante genérica que política pública é "o que o Estado (ator protagonista) faz ou deixa de fazer", por outro lado, de uma maneira mais prática Heideman (2006) propõe uma definição sugerindo que as políticas públicas consistem em "ações, práticas, diretrizes, fundamentadas nas funções do Estado por um governo, para resolver questões gerais e específicas da sociedade" (p. 29). Algumas outras definições enfatizam que as Políticas Públicas têm o papel de solucionar problemas, mas essa generalização acaba por deslocar o foco e minimizar um dos eixos das políticas públicas, que é, o embate em torno das ideias e dos interesses públicos, além de focar a atuação do governo, deixando de fora outros possíveis atores (SOUZA, 2006).

Para a construção deste artigo, que coloca as Políticas Públicas como um potente instrumento para promover a transição para sociedades sustentáveis, assumimos a definição proposta por Sorrentino et al. (2005), de que as Políticas Públicas (P.P.) podem ser entendidas como "procedimentos formais e informais que expressam a relação de poder e se destina à resolução pacífica de conflitos, assim como na estruturação e ao aprimoramento do bem comum" (p. 289). Esta definição não restringe o Estado à implantação das políticas públicas e reforça a importância de atuar na criação de espaços que possam contribuir com a melhoria das condições existenciais de seres humanos e não humanos. E para isso, é preciso ter responsabilidade sobre o empoderamento de atores sociais marginalizados. Por exemplo, criar condições para pequeno/as agricultor/as, no que diz respeito a sua capacidade de autogestão e resiliência, ou seja, dar acesso à extensão rural adequada, educação no campo, tecnologias apropriadas, acesso à insumos, estímulo à organização em cooperativas e redes de organização etc. É assumir um compromisso negligenciado historicamente.

Apesar de reconhecer a importância e relevância do Estado para dar legitimidade, amplitude e estrutura ao processo de mudança, não se defende a ideia de que o Estado deve ser a única instituição promotora de ações que visem resolver problemas sociais. Outros grupos da sociedade civil organizada podem e devem se engajar na promoção dessa sociedade desejada (HEIDEMAN, 2006), ou seja, assumimos sua importância mas defendemos a ideia da multicentralidade, de que, qualquer ator social pode ser protagonista neste processo, basta que o problema a ser enfrentado tenha características de interesse público (AGUM; RISCADO; MENEZES, 2015).

Logo, entendendo a importância do engajamento social na implementação de políticas públicas, se torna imprescindível a proposta trazida por Biasoli (2015), que propõe inclusão da Política do Cotidiano, no ciclo de construção de políticas públicas, a qual Frey (2000) define a partir de cinco etapas: perceber e definir os problemas; incluí-lo na agenda política; elaborar 
programas; implementação; avaliação e correção. A inclusão da Política do Cotidiano, consiste em assumir a fragilidade das forças sociais instituintes em participar do processo decisório e de implementação, buscando dar luz à necessária criação de condições materiais e imateriais que garantam a participação popular.

Acredita-se que para atuar na raiz dos complexos problemas socioambientais deve-se caminhar na construção de Políticas Públicas estruturantes, que, segundo Morimoto (2013, p. 53), é definida como:

Política pública estruturante consiste em uma proposta desenvolvida com a participação da comunidade interessada; visando o fortalecimento da mesma e a continuidade dos processos; com a preocupação de dialogar com as outras ações já em andamento naquele território; pautada na inclusão da diversidade de pessoas, ambientes e interesses; e que busque efeitos duradouros e justos.

Elas devem ser planejadas e executadas para serem duradouras, como também, para serem articuladas com outras iniciativas e consolidadas à ponto de possibilitar constante monitoramento e avaliação (BIASOLI, 2015). Para isso, é essencial o papel das forças instituintes, que são as forças advindas do conjunto de indivíduos que se unem, em prol de um Bem Comum (BIASOLI, 2015). Sendo o engajamento em rede, uma das suas expressões, que consegue ter força social, para estar, constantemente, pautando interesses sociais coletivos.

Assim, para dar organicidade e vitalidade à processos verdadeiramente contextualizados e comprometidos com a resolução dos problemas a partir da sua raiz, é preciso assumir a democratização radical, no sentido de criar condições para a participação de forças sociais instituintes e dar condições para a construção de Políticas Públicas estruturantes.

\section{Considerações Finais}

Apesar do cenário não ser novo ele evidencia problemas profundos e generalizados de um paradigma, sustentado pelos pilares do patriarcado, colonialismo e capitalismo. A lógica da mercantilização das relações se estende à todos os lugares em que este modelo social se estabelece, chegando num estado, da sociedade, em que os limites planetários estão próximos do "ponto de não retorno", aquele do qual as mudanças climáticas poderiam ser revertidas sem passarmos por grandes catástrofes naturais. Este está enunciado para se iniciar com uma variação de apenas $1^{\circ} \mathrm{C}$ (LENTON, 2011).

O tempo voa, numa assistida desesperança. A superexploração aponta a urgência de medidas, tanto emergenciais quanto fundadas em novas estruturas. É como, olhar os furos num bote velho, cheio de gente em pleno mar e saber que apenas tapar os buracos não resolve, e tampouco adianta 
jogar fora o bote em plena navegação. É preciso destituir o capitão, que joga as pessoas no mar para que empurrem à nado, o velho bote furado.

É tempo de enunciar qual caminho devemos seguir, de não renunciar à capacidade de sonhar e esperançar novos horizontes. De combater todo tipo de exploração humano-humano e humano-natureza, construir e consolidar, a partir da práxis coletiva, formas objetivas e subjetivas para promover uma cultura de humanidade na terra e com a Terra (SORRENTINO, 2020). É tempo de pensar Agroecológico, reafirmar as ancestralidades e enraizar ações locais para que, quando as folhas emergirem, consigam alcançar os céus.

Fortalecer laços, criar e viver em redes, gerar potência de ação e engajamento para pautar relações solidárias que se sustentem em políticas públicas estruturantes. Nutrir o incessante processo de educar ambientalmente a si mesmo e o seu território, na promoção de Sociedades Sustentáveis

Agradecimentos: Em especial à todas as pessoas do GT Construção de Conhecimento Agroecológico da ABA pelas colaborações coletivas na consolidação deste artigo. E ao Laboratório de Educação e Política Ambiental Oca (ESALQ/USP) pelo acolhimento, diálogos e pela luta diária em prol de mundo melhor.

\section{Referências}

ABRAMOVAY, R. A rede, os nós, as teias: tecnologias alternativas na agricultura. Revista de Administração Pública. Rio de Janeiro: FGV, v. 34, n.6, 2000.

AGUM, R.R., RISCADO, P.E.; MENEZES, M. Políticas públicas: conceitos e análise em revisão. Revista Agenda Política, v.3, n.2, p.12-42, 2015.

ALTIERI, M.; NICHOLLS, C. La Agroecología en tiempos del COVID19. Centro Latinoamericano de Investigaciones Agroecológicas, 2020 Disponível em: <http://celia.agroeco.org/wp-content/uploads/2020/05/ultimaCELIA-Agroecologia-COVID19-19Mar20-1.pdf> Acesso: 01 de Junho de 2020.

ASSOCIAÇÃO BRASILEIRA DE AGROECOLOGIA. Estatuto da Associação Brasileira de Agroecologia. Brasil: [s.n.]. Disponível em: <https://abaagroecologia.org.br/wp-content/uploads/2013/06/estatuto-ABA-2015.pdf $>, 2015$.

BARBIER, R. A pesquisa-ação na instituição educativa. [S.I.]: J.Zahar, 1985.

BARRETO, J.-M. Epistemologies of the South and Human Rights: Santos and the Quest for Global and Cognitive Justice. Indiana Journal of Global Legal Studies, v. 21, n. 2, p. 395-422, 2014.

BIASOLI, S. Institucionalização de políticas públicas de Educação Ambiental: subsídios para a defesa da política do cotidiano. Tese (Doutorado). Escola Superior de Agricultura Luiz de Queiroz. Centro de Energia Nuclear na Agricultura. $\quad$ Piracicaba, $2015 . \quad$ Disponível em: $<$ https://www.teses.usp.br/teses/disponiveis/91/91131/tde-11122015-151307/ptbr.php> 
BRANDÃO, C. R. Ubuntu: habitar um local, partilhar um lugar, compartir uma vida. In: Sorrentino, et al. (Orgs.) Educação, Agroecologia e Bem Viver: transição ambientalista para sociedades sustentáveis. Piracicaba. $\mathrm{MH}-$ Ambiente Natural, 2017. 344 p. Disponível em: <http://oca.esalq.usp.br/wpcontent/uploads/sites/430/2020/01/Educacao-agroecologia-e-bem-viver-

final.pdf>

CANELLAS, J.M.; ALVES, C.E.S. Caracterização das cadeias curtas de abastecimento de alimentos. In: enciclopédia biosfera, centro científico conhecer- Goiânia, v.14 n.25; 2017. Disponível em: $<$ https://www.researchgate.net/publication/317691949 CARACTERIZACAO D AS CADEIAS CURTAS DE ABASTECIMENTO DE ALIMENTOS>

CAPORAL, F.; COSTABEBER, J. Agroecologia e extensão rural: contribuições para a promoção do desenvolvimento rural sustentável. $2004 . \quad$ Disponível em: <http://www.sidalc.net/cgibin/wxis.exe/? IsisScript=AGB.xis\&method=post\&formato=2\&cantidad=1\&expre sion=mfn=218154 $>$. Acesso em: 25 jun. 2017.

DA COSTA, M. B. B. et al. Agroecologia no Brasil-1970 a 2015. Agroecología, v. 10, n. 2, p. 63-75, 2015.

DAROLT, M. R. Circuitos custos de comercialização de alimentos ecológicos: reconectando produtores e consumidores . In: NIEDERLE, P. A., ALMEIDA, L. DE e VEZZANI, F. M. (orgs.). Agroecologia: práticas, mercados e políticas para uma nova agricultura. Curitiba, Kairós, 2013, p. 139-170

DAVIS, M. A crise do coronavírus é um monstro alimentado pelo capitalismo. In: DAVIS, Mike, et al: Coronavírus e a luta de classes. Terra sem Amos: Brasil, 2020. p. 05 a 13. Disponível em: $<$ https://terrasemamos.files.wordpress.com/2020/03/coronavc3adrus-e-a-lutade-classes-tsa.pdf>

DIEGUES, A.C. Sociedades e comunidades sustentáveis. NUPAUB/USP, p. 7 , $2003 . \quad$ Disponível em: $<$ http://nupaub.fflch.usp.br/sites/nupaub.fflch.usp.br/files/color/comsust.pdf>.

DURU, M.; THEROND, O.; FARES, M. Designing agroecological transitions; A review. Agronomy for Sustainable Development. [S.I: s.n.]. , 2015. Disponível em: $<$ https://link.springer.com/article/10.1007/s13593-015-0318-x>

DYE, T.R. Mapeamento dos modelos de análise de políticas públicas. In: HEIDEMANN, F.G.; SALM, J.F. (Orgs.) Políticas públicas e desenvolvimento: bases epistemológicas e modelos de análise. Brasília: UNB, 2009, p. 99-129.

FARIA, M. V.; PEREIRA, J. A. A Rede de Economia Solidária do Algodão Agroecológico: Desenvolvimento Humano, Sustentabilidade e Cooperação entre os Produtores Rurais do Estado do Ceará. Organizações Rurais \& Agroindustriais, 2012, v. 14, n.3, 2012, pp. 395-408. Disponível em: $<$ https://ideas.repec.org/a/ags/orarao/146692.html> 
FAO. The State of Food Insecurity in the World 2015. Food and Agriculture Organization Publications, Rome, 2016a. Disponível em: $<$ http://www.fao.org/3/a-i4646e/index.html>.

FREY, K. Políticas Públicas: um debate conceitual e reflexões referentes à prática de políticas públicas no Brasil. Planejamento e políticas públicas, Brasília, n. 21, jun. 2000, 212-259.

GADOTTI, M. Economia Solidária como Práxis Pedagógica. 1. ed. São Paulo: Editora e Livraria Instituto Paulo Freire, 2009

GARRIDO, R. G.; GARRIDO, F. S. R. COVID-19: Um Panorama com ênfase em Medidas Restritivas de Contato Interpessoal. Saúde e Ambiente, v. 8, n. 2, 17 abr. 2020.

GLIESSMAN, S. Agroecology: Growing the Roots of Resistance. Agroecology and Sustainable Food Systems, v. 37, n. 1, p. 19-31, 1 jan. 2013.

GLIESSMAN, S. R. Agroecologia: processos ecológicos em agricultura sustentável. [S.I.]: Ed. Universidade Federal do Rio Grande do Sul, 2001.

GOODMAN, D.; S.B.; WILKINSON, J. (1990): Da lavoura às biotecnologias: agricultura e indústria no sistema internacional. Rio de Janeiro: Editora Campus; 204 p. Disponível em: <http://books.scielo.org/id/zyp2j>

GROSFOGUEL, R. Para Descolonizar os Estudos de Economia Política e os Estudos Pós-Coloniais: Transmodernidade, Pensamento de Fronteira e Colonialidade Global.In: Epistemologias do Sul. Coimbra: [s.n.], 2009. p. 383-417. GUZMÁN, E.S.; MONTIEL, M.S; HERNÁNDEZ, D.G.; SÁNCHEZ, I.G.; COLLADO, A.C. Canales cortos de comercializacion Alimentária em Andalucia. Instituto de Sociología y Estudos Campesinos. Universidad de Córdoba. Fundación Pública Andaluza Centro de Estudios Andaluces: Sevilla, IFO 14, 2012, 164p. Disponível em: $<$ https://www.juntadeandalucia.es/export/drupaljda/CCC alimentaria en Andal ucia 2012.pdf>

GUZZATTI, T. C.; SAMPAIO, C. A. C.; TURNES, V. A. Novas relações entre agricultores familiares e consumidores: perspectivas recentes no Brasil e na França. Organizações Rurais \& Agroindustriais, 2014, v. 16 (3). 2014. pp. 363-375.

HECHT, S. B. A evolução do pensamento Agroecológico. Agroecologia e Desenvolvimento. Los Angeles: AS-PTA. , 1993

HEIDMANN, F. G. Do sonho do progresso às políticas de desenvolvimento. In: HEIDMENN, F. G.; SALM, J. F. Políticas públicas e desenvolvimento. Brasília: UnB, 2006. p.23-39.

IPCC. Climate Change 2014: Synthesis Report. Contribution of Working Groups I, II and III to the Fifth Assessment Report of the Intergovernmental Panel on Climate Change. Geneva: [s.n.], 2015. 
KOO, J. R. et al. Interventions to mitigate early spread of SARS-CoV-2 in Singapore: a modelling study. The Lancet Infectious Diseases, v. 20, n. 6, p. 678-688, jun. 2020.

KROLOW, L. R; RIEDL, M. Cooperativismo e Agroecologia como elementos para o desenvolvimento regional. Anais do Seminário Internacional sobre Desenvolvimento Regional, 2., 2005, Santa Cruz do Sul-SC. Artigo completo em Anais. Disponível em: $<$ https://www.unisc.br/site/sidr/2004/planejamento/13.pdf>

LARANJEIRA, N. P. F. et al. PARA UMA ECOLOGIA DE SABERES: Revista Brasileira de Agroecologia; Edição Especial, v. 14, n. 2, 2 nov. 2019.

LEFF, E. Agroecologia e saber ambiental. Agroecologia e desenvolvimento rural sustentável, v. 3, n. 1, p. 36-51, 2002.

LEFF, E. Complexidade, Racionalidade Ambiental e Diálogo de Saberes. Educação \& Realidade, v. 34, n. 3, p. 17-24, 2009.

LENTON, T. M. Early warning of climate tipping points. Nature Climate Change, v. 1, n. 4, p. 201, 2011.

LEWNARD, J. A.; LO, N. C. Scientific and ethical basis for social-distancing interventions against COVID-19. The Lancet Infectious Diseases, v. 20, n. 6, p. 631-633, jun. 2020.

LIMA, F. A. X. Construção de redes e agroecologia: o papel dos atores sociais no desenvolvimento rural. INTERAÇÕES, Campo Grande, MS, v. 20, n. 1, p. 171-183, jan./mar. 2019.

MAGRINI, M.-B. et al. Agroecological transition from farms to territorialised agriFood systems: issues and drivers. In: BERGEZ, J.-E.; AUDOUIN, E.; THEROND, O. (Org.). . Agroecological transitions: from theory to practice in local participatory design. [S.I: s.n.], 2019. p. 69-98. Disponível em: $<$ https://link.springer.com/chapter/10.1007/978-3-030-01953-2 5 >

MAMELUND S-E. Social inequality a forgotten factor in pandemic influenza preparedness. Tidsskrift for Den norske legeforening. 2017. Disponível em: $<$ https://tidsskriftet.no/2017/05/global-helse/social-inequality-forgotten-factorpandemic-influenza-preparedness>

MANCE, E. A. A revolução das redes: a colaboração solidária como uma alternativa pós-capitalista à globalização atual. Petrópolis, RJ: Vozes, 1999. Disponível em: <http://euclidesmance.net/docs/rede.htm>

MANCE, E. A. A revolução das redes de colaboração solidária. Encontro Internacional de Economias Salesianas, Sevilha, 2005. Disponível em: $<$ http://www.solidarius.com.br/mance/biblioteca/A Revolucao das Redes de Colaboracao Solidaria.pdf>

MARQUES, L. Capitalismo e colapso ambiental. 3. ed. Campinas, SP: Editora da Unicamp, 2018. Disponível em: <http://books.scielo.org/id/s2y2y $>$. 
MARTINS, J.S. A modernidade do "passado" no meio rural. In: BUAINAIN, A.M. et al. O mundo rural no Brasil do século 21: a formação de um novo padrão agrário e agrícola. Brasília: Embrapa, 2014. Disponível em: $<$ https://www.embrapa.br/busca-de-publicacoes/-/publicacao/994073/o-mundorural-no-brasil-do-seculo-21-a-formacao-de-um-novo-padrao-agrario-eagricola>

MAX, N.; ELIZALDE, M.; HOPENHAYN, M. Desarrollo a escala humana. Una opción para el futuro. Cepaur. Fundación Dag Hammarskjold. Development Dialogue., v. rev, n. Número especial, 1986.

MORIMOTO, I.A. Direito e Educação Ambiental: estímulo à participação crítica e à efetiva aplicação de normas voltadas à proteção ambiental no Brasil. 2014. 456p. Tese (Doutorado em Ciência Ambiental) - Programa de Ciências Ambientais-PROCAM, Universidade de São Paulo, São Paulo, 2014. Disponível em: <https://www.teses.usp.br/teses/disponiveis/90/90131/tde29052014-211231/publico/TeselsisAkemiMorimoto.pdf>

NOGAARD, R. B. A Base Epistemológica da Agroecologia. In: Agroecologia: as bases científicas da agricultura alternativa. Rio de Janeiro: PTA/FASE, 1989. p. 42-48.

PEREIRA, V. S. Desenvolvimento à escala humana: uma análise em São Tomé das Letras - MG. Tese. 2011. Universidade Federal de Lavras/UFLA, 2011. Disponível em: <http://repositorio.ufla.br/sspui/handle/1/3123\%0A >.

PEREZ-CASSARINO, J.; DAMASCENO, A. D. Agroecologia, construção social de mercados e a constituição de sistemas agroalimentares alternativos: Uma leitura a partir da rede ecovida de agroecologia. In: NIEDERLE, P. A., ALMEIDA, L. DE e VEZZANI, F. M. (orgs.). Agroecologia: práticas, mercados e políticas para uma nova agricultura. Curitiba, Kairós, 2013, p. 171-214

PETERSEN, P.; ARBENZ, M. Aumento de escala em Agroecologia: uma questão política. Revista Agriculturas. v.14 n.1, 2018.

PETERSEN, PAULO. Agroecologia: Um antídoto contra a amnésia biocultural. In: Memória Biocultural: A importância ecológica das sabedorias tradicionais. $1^{\text {a }}$ ed. São Paulo: Expressão Popular, 2015. p. 272.

PETERSEN, PF; WEID, J. VON DER. Agroecologia: reconciliando agricultura e natureza. Informe Agropecuário, 2009. Disponível em: <http://aspta.org.br/wpcontent/uploads/2012/05/Agroecologia-reconciliando-agricultura-e-

natureza.pdf>. Acesso em: 10 jun. 2017.

SANTOS, B. DE S.; MENESES, M. P. Epistemologias do sul. EDIÇÕES AL ed. Palheira/Assafarge: G.C. Gráfica de Coimbra, LDA., 2009.

SANTOS, B. DE S. A gramática do tempo: para uma nova cultura política. 3. ed. São Paulo/SP: [s.n.], 2010. Disponível em: $<$ http://www.boaventuradesousasantos.pt/documentos/a gramatica do tempo. pdf>. Acesso em: 30 jun. 2017.

SANTOS, B.S. Para além do pensamento abissal: das linhas globais a uma ecologia de saberes. Novos Estudos - CEBRAP, n. 79, p. 71-94, nov. 2007.

Revbea, São Paulo, V. 15, № 7: 314-333, 2020. 
SANTOS, B. DE S. Um discurso sobre as ciências na transição para uma ciência pós-moderna. Estudos avançados, v. 2, n. 2, p. 46-71, 1988.

SÃO PAULO. Prefeitura Municipal. Relatório Situacional COVID-19: relatório técnico. São Paulo. 2020.2 Disponível em: $<$ https://www.prefeitura.sp.gov.br/cidade/secretarias/upload/saude/COVID19 R elatorio Sltuacional SMS 20200529.pdf>. Acesso em: 05 Jun. 2020.

SÃO PAULO. Prefeitura Municipal: Dados demográficos dos distritos pertencentes às Subprefeituras, c2020. Disponível em: $<$ https://www.prefeitura.sp.gov.br/cidade/secretarias/subprefeituras/subprefeitur as/dados demograficos/index.php?p=12758>. Acesso em: 05 Jun. 2020.

SILVEIRA, S. M. P. Rede Ecovida de Agroecologia: uma inovação estratégica para o desenvolvimento territorial sustentável na zona costeira catarinense? Revista Internacional Interdisciplinar INTERthesis, Florianópolis, v.10, n.2, p. 181-213, Jul./Dez. 2013a.

SILVEIRA, S. Redes de agroecologia: uma inovação estratégica para o desenvolvimento territorial sustentável - Estudo de caso de dois grupos do núcleo litoral catarinense da rede Ecovida de agroecologia no período de 2002 a 2012. Tese de Doutorado em Sociologia Política, Programa de pósgraduação em Sociologia Política, UFSC, 2013b. Disponível em: <https://repositorio.ufsc.br/handle/123456789/107616>

SINGER, P. Introdução a Economia Solidária. 1. ed. São Paulo, SP: Editora Fundação Perseu Abramo, 2002. Disponível em: $<$ https://fpabramo.org.br/publicacoes/wp-

content/uploads/sites/5/2018/04/Introducao-economia-solidaria-WEB-1.pdf>

SINGER, P. Economia solidária versus economia capitalista. Sociedade e Estado v. 16, n. 1-2, p., 2001.

SOUZA, C. Políticas Públicas: uma revisão da literatura. Sociologias, Porto Alegre, ano 8, oㅜ 16, jul/dez 2006, p. 20-45.

SORRENTINO, M. et al. Por una nueva cultura de la tierra, tierra y territorio: rutas de transición para sociedades sustentables. Carpeta Informativa del Centro Nacional de Educación Ambiental, Madrid, 2020. 40 p. Disponível em: <https://www.miteco.gob.es/es/ceneam/carpeta-informativa-delceneam/numeros-anteriores/carpeta-abril2020 tcm30-508381.pdf>.

SORRENTINO, M. et al. Educação Ambiental como política pública. Revista Educação e Pesquisa, São Paulo, v. 31, n. 2, p. 285-299, maio/ago. 2005.

WEISS, R. Max Weber e o problema dos valores: as justificativas para a neutralidade axiológica. Revista de Sociologia e Política, v. 22, n. 49, p. 113137, mar. 2014.

WEZEL, A. et al. Agroecology as a science, a movement and a practice. A review. Agronomy for Sustainable Development, v. 29, n. 4, p. 503-515, 2009. 